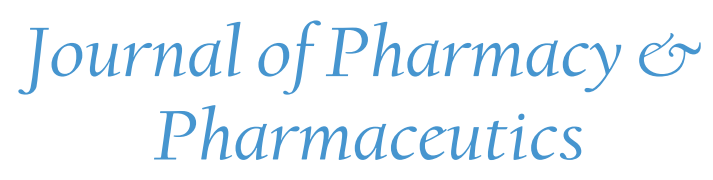

\title{
A Ceiling Dose with Furosemide in Systolic Heart Failure: A Myth or a Pertinent Clinical Consideration?
}

\author{
${ }^{1}$ Division of Clinical Pharmacy, Northwell Health, New York \\ ${ }^{2}$ Division of Clinical Pharmacy, Northwell Health Lenox Hill, New York \\ ${ }^{3}$ Division of Pulmonary Critical Care, Winthrop Hospital, Mineola, New York
}

William Heuser $^{1 *}$, Caitlyn Cummings ${ }^{1}$, Cheng-Hsiao Tai $^{2}$, Bejoy Maniara $^{1}$, Adel Hanna ${ }^{3}$

*Corresponding author: William Heuser, Pharm.D., Department of Pharmacy, St. John's University, Queens, New York, USA, E-mail: william.heuser08@my.stjohns.edu

\begin{abstract}
Loop diuretics are the diuretic of choice in chronic heart failure (CHF). By prohibiting the reabsorption of sodium and chloride in the thick ascending loop of Henle, they create a hypertonic environment in the lumen, thereby keeping water from being reabsorbed in the distal convoluted tubule (DCT) or collecting duct and promoting diuresis. Loop diuretics are very effective for symptomatic relief in $\mathrm{CHF}$, however there is a maximum effective dose by which higher doses will no longer improve diuresis but rather only subject the patient to side effects. Additionally, patients may also experience furosemide resistance by different mechanisms. While the true incidence of furosemide resistance is unknown, the phenomenon is a pertinent problem, which needs to be addressed to improve patient symptomatology. Focusing on the pharmacokinetic profile of furosemide, the half-life of furosemide is short. As a result, sodium retention can occur after furosemide administration, which is known as post diuretic salt retention. Furthermore, other parts of the tubule may play a role in the reabsorption and reuptake of sodium, specifically in the DCT or collecting duct, which offsets the effect of furosemide. Lastly, the concentration of furosemide at the site of action may be significantly reduced as the patient's CHF worsens. Limiting salt intake and avoiding the use of non-steroidal anti-inflammatory drugs (NSAIDs) should always be recommended before declaring a patient to be resistant to furosemide. The clinician should consider increasing furosemide dosing frequency and/or adding another diuretic (thiazide-like); depending on the physiologic mechanism of furosemide resistance, one strategy may take preference over the other.
\end{abstract}

Received date: November 10, 2015

Accepted date: August 31, 2016

Published date: September 05, 2016

Citation: Heuser, W., et al. A Ceiling Dose with Furosemide in Systolic Heart Failure: A Myth or a Pertinent Clinical Consideration?. (2016) J Pharm Pharmaceutics 3(2): 83-89.

DOI: $10.15436 / 2377-1313.16 .011$

Keywords: Furosemide; Ceiling dose; Loop diuretics; Refractory CHF

\section{Materials and Methods}

Heart failure (HF) is a complex clinical syndrome that results from structural (e.g. cardiac remodeling) or functional (e.g. decreased ventricular compliance) impairment of ventricular filling or ejection of blood ${ }^{[1]}$. The clinical hallmark of HF is a weakened heart, which is unable to efficiently pump and supply blood to tissues and vital organs of the human body. Consequently, patients commonly present with symptoms including shortness of breath, dyspnea, weakness, fatigue, and edema, which in severe cases requires hospitalization. According to the American Heart Association (AHA), the prevalence of heart failure in the United States in 2006 is approximately 5.1 million people, and is expected to rise over the next four decades with an estimated 772,000 new HF cases by the year $2040^{[2,3]}$. HF is a disease state that frequently affects the elderly and with the increase in the elderly population there 
will be a noticeable increase in rate of hospitalization due to HF in the future. Current AHA guidelines recommend the use of angiotensin-converting enzyme (ACE) inhibitors or angiotensin II receptor blockers (ARB) and a beta-blocker with loop diuretics, hydral-nitrates, and aldosterone antagonists as adjunctive therapy, for the maintenance of heart failure ${ }^{[1]}$. The scope of this article will emphasize on the placement, clinical use, and issues associated with loop diuretic use. Diuretics play a major role in the symptomatic treatment of HF in patients with evidence of fluid retention. Diuretics inhibit the reabsorption of sodium or chloride at specific sites in the renal tubules, resulting in an increase production or urine and fluid excretion. Loop diuretics such as furosemide, torsemide, and bumetanide act on the thick ascending limb of the loop of Henle resulting in more diuresis as compared with thiazide diuretics that act on the distal tubules of the kidney. Loop diuretics tend to work faster and have a greater effect in the inhibition of sodium reabsorption than thiazide diuretics making loop diuretics such as furosemide the drug of choice in HF associated edema. However, loop diuretics, like furosemide have a dose dependent effect on the degree of natriuresis and diuresis. When a maximum threshold concentration of the diuretic is reached any further increase in drug concentration will yield no change in natriuresis and dieresis ${ }^{[4]}$. This phenomenon is known as the ceiling dose, which is problematic for heart failure patients that require aggressive diuresis and become refractory to high doses of furosemide.

\section{Frank starling mechanism}

When using loop diuretics, such as furosemide, it is important to note that the diuretic effect is dose-dependent ${ }^{[5]}$. At low doses, little to no diuresis is seen. However, as you increase the dose of the diuretic, the extent of diuresis progressively increases. Eventually, after gradually increasing the diuretic dose, a plateau is reached; higher doses will not produce any further diuresis. This dose is known as the maximum effective dose, commonly referred to as the "ceiling effect"[6].

Understanding the Frank-Starling mechanism is paramount in order to appreciate the practical and clinical use of diuretics in heart failure patients. In the early $20^{\text {th }}$ century, Ernest starling and colleagues discovered that increased venous return to the heart (increasing the pre-load), led to increased filling pressures (LVEDP) of the ventricle, which resulted in an increase in stroke volume $(\mathrm{SV})^{[7]}$. Ejection fraction $(\mathrm{EF})$, measured via an echocardiogram, remains a vital component in the diagnosis and differentiation of patients with systolic heart failure. Patients with systolic heart failure have EF $\leq 40 \%$ (Normal EF is approximately $\geq 60 \%$ ), indicating a classic characteristic of heart failure; the inability of the heart to pump efficiently to meets the metabolic needs of the body (i.e. pump failure). The relationship between $\mathrm{EF}$ and $\mathrm{SV}$ is important to understand as cardiac output (or cardiac index, which takes BMI into consideration) is fundamental to the principles of Frank Starling mechanism $^{[8]}$. EF is defined as the fraction of blood ejected from the left ventricle relative to end diastolic volume; therefore EF is simply a ratio of SV to $\mathrm{EDV}^{[9]}$. To apply this ratio, many patients with systolic heart failure have increased EDV as a result of compensatory mechanisms to increase preload and decrease SV due to left ventricular hypertrophy, consistent with eccentric hypertrophy. This essentially will cause the EDV to increase with a reduction in the SV resulting in decreased ejection fraction. In comparison, patients with diastolic failure, characterized by concentric hypertrophy, have preserved EF as a result of both the EDV and the SV to be decreased simultaneously such that EF does not change appreciably. Although diuretics do not intrinsically modify cardiac remodeling, diuretics can reduce congestion symptomatology by reducing EDV once these patients have reached a plateau on Starlings curve. Is important to not reduce preload excessively in patients with systolic heart failure as this can trigger cardiac decompensation. Therefore, it is important to utilize diuretics once the patient has reached a point where reduction in EDV will correspond to symptomatic relief.

In regards to furosemide, a ceiling effect is usually seen when it is administered as $40 \mathrm{mg}$ intravenously, or $80 \mathrm{mg}$ orally (oral bioavailability of furosemide is $\sim 50 \%)^{[6]}$. In general, doses greater than these, via their respective routes, will not provide any extra diuretic effect. Instead, exceeding furosemide's maximum effective dose will increase an individual's risk of adverse events, such as electrolyte imbalances and ototoxicity, and also increase the individual's risk of developing resistance to furosemide $^{[10]}$

In order to comprehend the reason as to why furosemide has a ceiling effect, it is essential to understand the Frank-Starling Law. The Frank-Starling Law states that there is a relationship between cardiac output (CO), or stroke volume (SV), and left ventricular end diastolic pressure (LVEDP), or end diastolic volume (EDV). EDV represents the volume of blood that remains in the ventricles after diastole (ventricular relaxation). This opposes end systolic volume (ESV), in that ESV represents the volume of blood that remains in the ventricles after systole (ventricular contraction). SV represents the volume of blood that is ejected from the heart with each heartbeat, which is the difference between EDV and ESV. By multiplying the SV by heart rate (HR), you are able to determine CO. The LVEDP is dependent on the EDV, and aids in determining preload. Preload is known as a "filling pressure". In other words, preload represents the extent to which the left ventricle stretches at the end of diastole, as a result of the left ventricular EDV. This differs from after load, in that after load represents an "ejection pressure". In other words, after load represents the arterial resistance that the heart must overcome in order to eject the contents of the left ventricle during systole. As your EDV increases, your preload increases. This allows for a stronger contraction, which leads to greater SV and, ultimately, a higher CO. However, if your preload is low, or if your after load is high, your SV and CO will be relatively lower. In such a scenario, fluid may accumulate in the heart, causing congestive heart failure $(\mathrm{CHF})^{[11]}$ (Figure 1). In order to relieve fluid accumulation during CHF, loop diuretics, such as furosemide, are used ${ }^{[6]}$.

Ultimately, the Frank-Starling Law states that, as your preload increases, your cardiac output increases ${ }^{[11]}$. Since furosemide will decrease cardiac filling, it will decrease preload, subsequently decreasing SV and CO. After a certain dose, furosemide may diuresis an individual to a point when preload can no longer decrease. This is known as the "ceiling effect" or "maximum effective dose" of diuretics. 


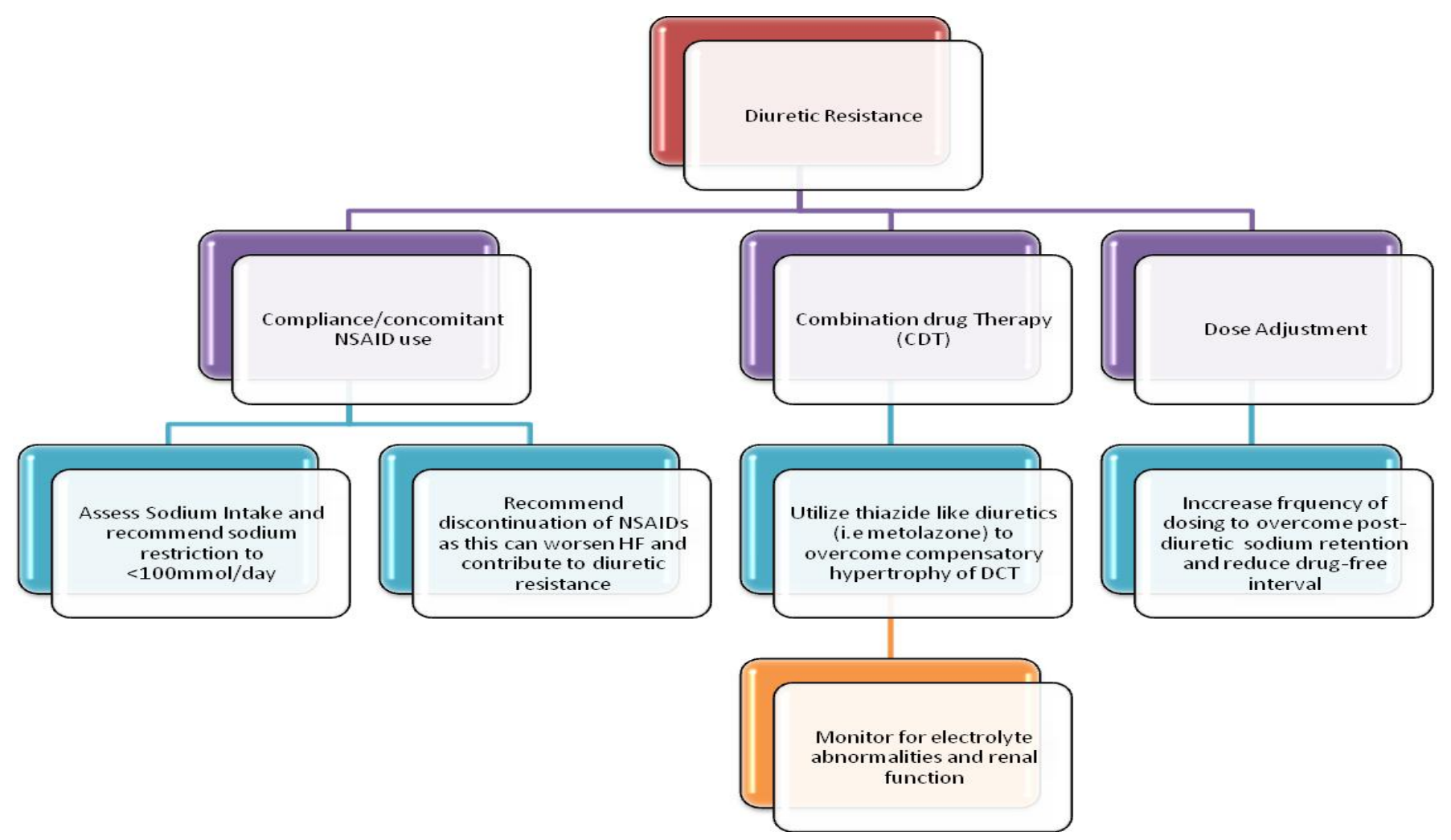

Figure 1: Strategies for managing diuretic resistance in congestive Heart failure.

Table 1: Pharmacodynamic/Pharmacokinetics of commonly used Loop Diuretics in systolic Heart failure.

\begin{tabular}{|c|c|c|c|c|c|c|c|}
\hline \multicolumn{8}{|c|}{ Loop Diuretics* } \\
\hline Drug name & $\begin{array}{l}\text { Mechanism } \\
\text { of Action }\end{array}$ & Site of Action & $\begin{array}{l}\text { Onset of } \\
\text { action }\end{array}$ & $\begin{array}{l}\text { Duration } \\
\text { of action }\end{array}$ & $\begin{array}{l}\% \text { Oral } \\
\text { Bioavaliability }\end{array}$ & $\%$ Natriuresis & Dosing $¥$ \\
\hline $\begin{array}{l}\text { Furosemide } \\
\text { (Lasix) }\end{array}$ & \multirow[t]{3}{*}{$\begin{array}{l}\text { Inhibits } \\
\text { reabsorption of } \\
\text { sodium thus } \\
\text { causing } \\
\text { increased } \\
\text { excretion of } \\
\text { water }\end{array}$} & $\begin{array}{l}\text { Ascending } \\
\text { loop of Henle } \\
\text { \& distal renal } \\
\text { tubule }\end{array}$ & $\begin{array}{l}\text { Oral: } 0.5-1 \\
\text { hour } \\
\text { IV: } \sim 5 \mathrm{~min}\end{array}$ & $\begin{array}{l}\text { Oral: } 6 \text { - } 8 \\
\text { hours } \\
\text { IV: } 2 \text { hours }\end{array}$ & $47 \%-64 \%$ & \multirow[t]{3}{*}{$25 \%$} & $\begin{array}{l}\text { Oral: } 20 \text { - } 40 \mathrm{mg} \text { once or } \\
\text { twice daily } \\
\text { (MTDD: } 600 \mathrm{mg} \text { ) } \\
\text { IV: } 20-40 \mathrm{mg} / \text { dose } \\
\text { (Max dose: } 200 \mathrm{mg} / \text { dose) }\end{array}$ \\
\hline $\begin{array}{l}\text { Torsemide } \\
\text { (Demadex) }\end{array}$ & & $\begin{array}{l}\text { Ascending } \\
\text { loop of Henle } \\
\& \text { distal renal } \\
\text { tubule }\end{array}$ & $\begin{array}{l}\text { Oral: With- } \\
\text { in } 1 \text { hour }\end{array}$ & $\begin{array}{l}\text { Oral } \sim 6-8 \\
\text { hours }\end{array}$ & $\sim 80 \%$ & & $\begin{array}{l}\text { Oral: } 10-20 \mathrm{mg} \text { once } \\
\text { daily } \\
\text { (MTDD: } 200 \mathrm{mg} \text { ) }\end{array}$ \\
\hline $\begin{array}{l}\text { Bumetanide } \\
\text { (Bumex) }\end{array}$ & & $\begin{array}{l}\text { Ascending loop } \\
\text { of Henle \& } \\
\text { proximal renal } \\
\text { tubule }\end{array}$ & $\begin{array}{l}\text { Oral: } 0.5-1 \\
\text { hour } \\
\text { IV: } 2-3 \\
\text { mins }\end{array}$ & $\begin{array}{l}\text { Oral: } 4-6 \\
\text { hours } \\
\text { IV: } 2-3 \\
\text { hours }\end{array}$ & $59 \%-89 \%$ & & $\begin{array}{l}\text { Oral: } 0.5-1 \mathrm{mg} \text { once or } \\
\text { twice daily } \\
\text { IV: } 0.5-1 \mathrm{mg} / \mathrm{dose} \\
\text { (MTDD: } 10 \mathrm{mg} \text { ) }\end{array}$ \\
\hline
\end{tabular}

*Potency/dose conversion of Furosemide:Torsemide:Bumetanide --> $40 \mathrm{mg}: 20 \mathrm{mg}: 1 \mathrm{mg}$

$¥ D$ osing is based off 2013 ACCF/AHA 2013 Heart Failure Guidelines

$M T D D=$ Maximum total daily dose

\section{Mechanisms and management of diuretic resistance in chronic refractory heart failure patients}

Volume overload and congestion is an important clinical target in chronic heart failure patients and often indicates inadequate symptom control or resistance to standard therapy with loop diuretics (Table 1). The subset of heart failure patients with loop diuretic resistance remain an important clinical challenge for many health care providers as multiple mechanisms account for diuretic resistance. There are several mechanisms in which maximally dosed furosemide fails to adequately control salt and water retention in chronic heart failure (CHF). The reason this phenomenon is important to clinical practice is supported by a retrospective analysis, which established a correlation between heart failure patients and loop diuretic resistance. These patients were associated with an increase in mortality, sudden death, and pump failure death ${ }^{[12]}$. In addition, resistance to loop diuretics is a major concern for chronic heart failure patients because of the correlation between the use of exceedingly high diuretic doses and increased mortality, which suggests that loop diuretic resistance should be considered as an indicator of prognosis in patients with CHF. Be- 
cause of this association, there is a great need to understand the mechanisms of furosemide resistance in order to optimize treatment in CHF. Despite their unproven effect on mortality, loop diuretics undeniably provide symptomatic relief of congestive symptoms, making them an adjunctive therapy in combination with ace inhibitors and beta blockers in most patients ${ }^{[13]}$. Often times in the more advanced stages of heart failure, diuretic resistance develops as a result of multiple mechanisms, blunting the diuretic effect and increasing the rates of readmission as a result of decompensation secondary to fluid overload. There are many strategies to overcome diuretic resistance including alterations in dose frequency, restriction of sodium intake, and utilization of combination drug therapy. This section will focus and highlight on the mechanisms of diuretic resistance and the treatment strategies and their considerations in clinical practice, used to manage this problem.

The half-life of furosemide is short, at approximately 6 hours, so when the concentration of the drug at the site of action is no longer sufficient to block the $\mathrm{Na}^{+} / \mathrm{K}^{+} / 2 \mathrm{Cl}^{-}$cotransporter, a compensatory increase in sodium retention occurs until the next dose of drug is administered; this is known as post-diuretic salt retention. Reducing the drug-free interval in patients with chronic heart failure is an important clinical consideration, as keeping a constant exposure of the drug at the site of action in the renal tubules will effectively elicit a constant and adequate diuretic response. Continuous intravenous infusion of a loop diuretic may obviate this post-diuretic salt retention and represents an additional mechanism to overcome diuretic resistance if other treatment modalities have failed. To date there are many controlled studies which have effectively compared the efficacy of intermittent intravenous bolus administration of a loop diuretic with continuous infusion in patients with advanced heart failure. Many of these studies have demonstrated that continuous infusion of a loop diuretic essentially eliminates post-diuretic salt retention and allows for an additional safe and effective treatment in patients refractory to oral loop diuretics ${ }^{[14-17]}$ Post-diuretic salt retention is an essential mechanism contributing to diuretic resistance especially when the diuretic is not dosed properly and can be compounded with poor sodium intake control. More frequent administration of the drug (i.e., two to three times daily) can potentially overcome the effect of post diuretic salt retention by limiting the amount of time that the body is free of drug. Other options that clinicians have looked into was the utilization of more potent diuretics like bumetanide which is 40 times more potent than furosemide in addition to its better bioavailability ( $80 \%$ vs. $40 \%$ for bumetanide and furosemide respectively $)^{[18]}$. Despite bumetanide's increased potency and bioavailability, both drugs are equally effective when equipotent doses are administered $^{[19,20]}$.

The braking phenomenon is another mechanism of resistance in which long-term use of furosemide may be associated with increased sodium reabsorption in other parts of the nephrons (i.e., collecting duct, proximal and distal convoluted tubules). Hypertrophy and hyperplasia in epithelial cells of the distal convoluted tubule (DCT) due to increased solute load and flow rate is one proposed mechanism. In the DCT, there are $\mathrm{Na}^{+} /$ $\mathrm{Cl}^{-}$cotransporters responsible for about $5 \%$ of salt reabsorption. Due to furosemide blockade at the thick ascending loop of Henle, sodium travels downstream where there is the potential for hyper functioning of the contransporters in the DCT to reabsorb sodium $^{[21]}$. The support for this mechanism of furosemide resis- tance first comes from a rat study performed by Kaissling, et al. After rats were continuously exposed to furosemide treatment coupled with high salt intake, both the basolateral cell membrane of the DCT cells and the number of DCT cells significantly increased compared to control rats ${ }^{[22]}$ Supporting this finding, a small human trial found that previous exposure to furosemide resulted in less fractional excretion of sodium compared to patients not exposed to furosemide, presumably from the braking effect; when these same patients were treated with furosemide plus chlorothiazide, a greater natruiretic effect was seen ${ }^{[23]}$. In order to alleviate this potential mechanism of resistance, combination drug therapy with an agent that works to inhibit the hyper functioning of the DCT proves to be beneficial.

Combination drug therapy (CDT) with thiazide-type diuretics is a novel therapeutic approach to overcoming many of the resistance mechanisms present in diuretic resistance. There are potential benefits of combination diuretic therapy such as fluid removal with resolution of volume overload and congestion in patients with impaired renal function refractory to loop diuretics $^{[24]}$. Although CDT has not yet been proven to show a decrease in mortality in refractory CHF patients, improved diuresis could prevent prolonged hospital stay and facilitate earlier hospital discharge. Contemporary literature shows that it has been difficult to correlate weight loss or net fluid loss during heart failure hospitalization with subsequent outcomes ${ }^{[25]}$. Despite increasing the frequency of furosemide dosing and/or changing route of administration (e.g. oral, intravenous bolus or continuous infusion), many patients with chronic advanced heart failure often reach a point where high dose furosemide is unable to overcome diuretic resistance. The addition of a thiazide or thiazide-like diuretic with loop diuretics has been shown to be effective in establishing a diuresis in patients refractory to monotherapy with a loop diuretic. It is important to note that according to the RALES study, spironolactone, which is a potassium-sparing diuretic has shown mortality benefit due to its ability to prevent cardiac remodeling ${ }^{[26]}$. The study did not assess the effects of combination diuretic therapy with furosemide on mortality. There have been many studies that have assessed the efficacy of combination therapy with thiazide diuretics with loop diuretics in CHF. One particular study by Rosenberg, et al. looked at the efficacy and safety of combination therapy with metolazone and loop diuretics in outpatients with refractory heart failure. This study showed that low dose metolazone $(\leq$ $5 \mathrm{mg}$ ) in combination with loop diuretics, is an effective and relatively safe treatment in contemporary outpatients with refractory $\mathrm{HF}^{[27]}$. Another study looked at the administration of 25 to $100 \mathrm{mg}$ of hydrochlorothiazide in fluid overloaded patients refractory to monotherapy of loop diuretics and results suggest hydrochlorothiazide to be very effective in patients with severe $\mathrm{CHF}$ and impaired renal function ${ }^{[28]}$. Based on the available literature to date, there does not seem to be a theoretical benefit or advantage of using metolazone over any other thiazide diuretic, despite metolazone's possible inhibition of proximal convoluted tubule that may add additive diuretic effect ${ }^{[29]}$.

In order to appreciate the benefits of CDT with thiazides, it is important to understand that thiazide diuretics work synergistically to inhibit the compensatory hypertrophy of the DCT through its ability to block reabsorption in this part of the nephron. In comparison to loop diuretics, which inhibit the reabsorption of approximately $25 \%$ of filtered sodium, thiazide diuretics block the reabsorption of 5 to $10 \%$ of filtered sodium ${ }^{[30]}$. 
Although considered first line therapy according to the JNC8 guidelines for hypertension, there use as monotherapy in heart failure is limited primarily due to their weak natriuretic effect. CDT provides a logical treatment for clinicians in patients with refractory fluid overload based on the pathophysiological mechanisms that account for the hypertrophy but, clinical adverse effects of CDT are common and must be taken into consideration. Consistent with the mechanism of action of both loop and thiazide diuretics, electrolyte disturbances are common and if not treated it can lead to serious and life threatening arrhythmias ${ }^{[31]}$. Hypokalemia is very common with CDT despite aggressive potassium supplementation. Spironolactone may provide benefit in these patients not only due to their mortality benefit, but due to their intrinsic potassium sparing effects that can offset the hypokalemia. Hypokalemia is often associated with hypochloremic metabolic alkalosis because bicarbonate ions are retained and chloride urine excretion typically exceeds sodium urine excretion. In addition, hypomagnesia that is usually present with these agents can worsen the extent of hypokalemia and supplementation of magnesium can aide in correcting the potassium imbalance as magnesium is correlated with potassium. Although hyponatremia is less common than hypokalemia, hyponatremia has been used as a negative prognostic indicator in heart failure patients and vigilance should be used to monitor this electrolyte imbalance $^{[32]}$.

Weighing the risks and benefits of CDT is an important clinical consideration and current recommendations suggest the use of combined loops and thiaizde diuretic combination as an appropriate approach in fluid refractory patients. Optimization of the loop diuretic therapy is essential and an adequate trial of a loop diuretic with doses between 160 - $320 \mathrm{mg}$ /day of intravenous furosemide should be utilized. Thiazide diuretic dosing is available through the American College of Cardiology/American Heart Association guidelines and include oral metolazone 2.5 to $10 \mathrm{mg}$ once daily (or $2.5 \mathrm{mg}$ to $5 \mathrm{mg}$ once or twice daily), oral hydrochlorothiazide 25 to $100 \mathrm{mg}$ once or twice daily, or intravenous chlorothiazide 500 to $1,000 \mathrm{mg}$ once or twice daily ${ }^{[33]}$. Should CDT therapy be initiated careful observation and frequent monitoring of renal function and electrolytes should be done attentively. CDT offers a potential benefit of symptomatic relief for HF patients with fluid overload refractory to furosemide treatment. However, studies focusing on using morbidity, mortality and/or safety endpoints are necessary to resolve the uncertainties regarding the balance between safety and clinical benefit of CDT.

Furosemide is 91 to $99 \%$ protein bound to albumin and reaches the tubular lumen primarily via active secretion and not by glomelular filtration or passive diffusion ${ }^{[34]}$. Dosing of furosemide in patients with renal insufficiency has been a major topic of discussion among clinicians as many question as to whether or not the drug is actually reaching the site of action to be able to elicit an appropriate diuretic response. In renal insufficiency, secretion of many of the loops diuretics (including furosemide) is reduced to a significant extent predominantly due to accumulation of endogenous organic anions competing with the loop diuretics for the receptor sites of the organic anion transporter ${ }^{[35]}$. In essence, in order to overcome this competitive inhibition and to obtain therapeutic doses for diuresis higher doses are often warranted in heart failure patients with renal impairment. Furosemide is a highly albumin bound drug and needs to get secreted by the organic anion transporter (OAT3) pump into the lumen of proximal tubule of the kidney; otherwise, it does not get to the site of action since it is not dependent on glomerular filtration or passive diffusion. In CHF, there is usually some impairment in the kidneys and in renal blood flow. This can translate into a build-up of other substrates (both endogenous and exogenous) for the OAT3 pump, thus leading to less drug delivery and less effective dieresis ${ }^{[30]}$. Supporting this, Brater, et al. conducted a small study, which showed that CHF patients experienced prolonged absorption of furosemide, which translated into decreased concentrations of the drug at the site of action compared to controls. Additionally, the dose response curve of furosemide (40 mg orally) was shifted down and right in patients with chronic heart failure compared to healthy controls. Heart failure patients secreted significantly less sodium in the urine (downward shift) and fewer drugs got to the site of action (rightward shift) ${ }^{[36,37]}$. Despite the requirement for higher diuretic doses it is important to realize that furosemide is dose dependent and a recent study done by Eshaghian, et al. involving 1354 patients with advanced systolic heart failure showed that there was a decrease in survival with increasing diuretic dose; there must a balance between clinical benefit and overdiuresis ${ }^{[38]}$.

Pharmacodynamic and pharmacokinetic effects of diuretic resistance include delayed absorption of the diuretic, reduced secretion of the diuretic into the tubular lumen, compensatory retention of sodium after the effective period of the diuretic and finally hypertrophy and hyperplasia of epithelial cells of the distal convoluted tubule (DCT) ${ }^{[30]}$. Prior to altering these mechanisms it is important to rule out non-compliance by ensuring salt restriction $<100 \mathrm{mmol} /$ day or concomitant medication intake (i.e. NSAIDs). In those patients that are exceeding greater than the daily-recommended amount of sodium for a $\mathrm{CHF}$ patient ( $>100 \mathrm{mmol} /$ day) will in essence alter the balance between naturiesis afforded by the LD and the compensatory post diuretic salt retention. By limiting the amount of sodium intake to $<100 \mathrm{mmol} /$ day the $\mathrm{LD}$ is able to effectively induce enough natriuresis without a compensatory increase in sodium retention that is enough to "wash out" the effect of the diuretic per sec ${ }^{[39]}$. Utilizing a 24 hour salt excretion test in addition to measuring the amount of diuretic in the urine may have some utility in verifying compliance and may provide useful information to the clinician in a limited number of patients ${ }^{[39]}$.

Non-steroidal anti-inflammatory drugs (NSAIDs), which have been effectively used in patients for relief of inflammation and pain, can in fact contribute significantly to apparent diuretic resistance as a direct result of their mechanism of action. In the ACCF/AHA HF guidelines, NSAIDs are labeled as a harmful class of drugs with a recommendation to avoid in $\mathrm{HFrEF}^{[1]}$. First of all; NSAIDs have a vasoconstricting effect on the afferent arteriole, thus decreasing blood flow and furosemide's ability to get to the nephrons and ultimately the site of action. More importantly, prostaglandins in the kidney vasodilate and inhibit the reabsorption of sodium in the thick ascending loop of Henle. By their mechanism of action as cyclooxygenase inhibitors (COX-1 and 2), NSAIDs inhibit prostaglandin synthesis and thereby add to water and salt retention ${ }^{[1,40]}$. A study in 1986 looked at the administration of prostaglandin E2 in indomethacin treated rats and the results showed a restorative natriuretic response to furosemide, verifying the blunted effects on natriuresis induced by NSAIDs ${ }^{[41]}$. By blunting the natriuretic 
effect and causing sodium retentive effects increases the risk of hospitalization in heart failure patients as indexed by the FDA labeling on NSAIDs. Because inhibiting the production of prostaglandins in effect diminishes their renal protectiveness in heart failure patients, discontinuing NSAIDS will result in countless advantages.

\section{Conclusion}

The ceiling effect is pertinent phenomenon that is important in clinical practice, as studies have shown increase in mortality, sudden death, and pump failure death in heart failure patients who have developed diuretic resistance that would only be amenable with higher diuretic doses. In addition, diuretic resistance has also contributed to the increasing rates of rehospitalizations as diuretics fail to provide symptomatic relief and prevent cardiac decompensation. Individuals who develop or suffer from diuretic resistance require higher diuretic doses predisposing them to adverse effects such as worsening renal failure, electrolyte imbalances, and ototoxicity without any additional benefits and increase in diuresis. Therefore, it is crucial that healthcare providers are aware of this phenomenon and the available options to manage it, as diuretic resistance and the ceiling effect are drawbacks in the management of heart failure patients. Patients with refractory heart failure with high oral or intravenous bolus doses of diuretics may be candidates to continuous infusion diuresis as it seems to produce constant plasma drug concentration with a more uniform diuretic and natriuretic effect and greater safety profile ${ }^{[42]}$. More importantly, available studies support the use of CDT; combining loop diuretics like furosemide with thiazide-type diuretics like metolazone is effective and relatively safe option when fluid overload is refractory to conventional therapy. Conclusively, heart failure patients suffering from fluid overload and decompensation who are refractory to conventional high dose furosemide due to diuretic resistance and the ceiling effect is a clinical problem that healthcare providers should be conscious of and know how to manage with the available treatment options, specifically CDT.

Conflict of Interests: The authors declare that they have no conflict of interest.

\section{References}

1. Yancy, C.W., Jessup, M., Bozkurt, B., et al. 2013 ACCF/AHA guideline for the management of heart failure: A report of the American College of Cardiology Foundation/American Heart Association Task Force on practice guidelines. (2013) Circulation 128(16): e240-327.

2. Go, A.S., Mozaffarian, D., Roger, V.L., et al. Heart disease and stroke statistics--2013 update: a report from the American Heart Association. (2013) Circulation 127(1): e6-e245.

3. Owan, T.E., Redfield, M.M. Epidemiology of diastolic heart failure. (2005) Prog Cardiovasc Dis 47(5): 320-332.

4. Brater, D.C., Day, B., Burdette, A., et al. Bumetanide and furosemide in heart failure. (1984) Kidney Int 26(2):183-189.

5. Veeraveedu, P.T., Watanabe, K., Ma, M., et al. Comparative effects of torsemide and furosemide in rats with heart failure. (2008) Biochem Pharmacol 75(3): 649-659.

6. Brater, D.C., Voelker, J.R. Use of diuretics in patients with renal disease. In: Pharmacotherapy of Renal Disease and Hypertension (Contemporary Issues in Nephrology). (1987) Churchill Livingstone: 17.
7. Lakatta, E.G. Length modulation of muscle performance: Frank Starling Law of the heart. The Heart and Cardiovascular System. (1992) Raven Press Publishers1325-1351.

8. Katz, A.M. Ernest Henry Starling, his predecessors, and the "Law of the Heart." (2002) Circulation 106(23): 2986-2992.

9. Sanderson, J.E. Heart Failure with normal Ejection Fraction. (2007) Heart 93(2): 155-158.

10. Asare, K. Management of loop diuretic resistance in the intensive care unit. (2009) Am J Health Syst Pharm 66(18): 1635-1640.

11. Vincent, J.L. Understanding cardiac output. (2008) Crit Care 12(4): 174.

12. Neuberg, G.W., Miller, A.B., O'Connor, C.M., et al. Diuretic resistance predicts mortality in patients with advanced heart failure. (2002) Am Heart J 144(1): 31-38.

13. Packer, M., Cohn, J.N., Abraham, W.T. Consensus recommendations for the management of chronic heart failure. (1999) Am J Cardiol 83(2A): 1A-38A.

14. Lahav, M., Regev, A., Ra'anani, P., et al. Intermittent administration of furosemide vs continuous infusion preceded by a loading dose for congestive heart failure. (1992) Chest 102(3): 725-731.

15. Van Meyel, J.J., Smits, P., Dormans, T., et al. Continuous infusion of furosemide in the treatment of patients with congestive heart failure and diuretic resistance. (1994) J Intern Med 235(4): 329-334.

16. Dormans, T.P., van Meyel, J.J., Gerlag, P.G. et al. Diuretic efficacy of high dose furosemide in severe heart failure: bolus injection versus continuous infusion. (1996) J Am Coll Cardiol 28(2): 376-382.

17. Ferguson, J.A., Sundblad, K.J., Becker, P.K., et al. Role of duration of diuretic effect in preventing sodium retention. (1997) Clin Pharmacol Ther 62(2): 203-208.

18. Brater, D.C., Day, B., Burdette, A., et al. Bumetanide and furosemide in heart failure. (1984) Kidney Int 26(2): 183-189.

19. Abrams, J. Intramuscular bumetanide and furosemide in congestive heart failure. (1981) J Clin Pharmacol 21(11-12): 673-679.

20. Sagar, S., Sharma, B.K., Sharma, P.L., et al. A comparative randomized double-blind clinical trial of bumetanide and furosemide in congestive cardiac failure and other edema states. (1984) Int J Clin Pharmacol Ther Toxicol 22(9): 473-478.

21. Colucci, W., Sterns, R. Use of diuretics in patients with heart failure. (2016) UpToDate.

22. Kaissling, B., Bachmann, S., Kriz, W. Structural adaptation of the distal convoluted tubule to prolonged furosemide treatment. (1985) Am J Physiol 248(3 Pt 2): F374-F381.

23. Loon, N.R., Wilcox, C.S., Unwin, R.J. Mechanism of impaired natriuretic response to furosemide during prolonged therapy. (1989) Kidney Int 36(4): 682-689.

24. Jentzer, J.C., DeWald, T.A, Hernandez, A.F. Combination of Loop Diuretics with Thiazide-Type Diuretics in Heart Failure. (2010) J Am Coll Cardiol 56(19): 1527-1534.

25. Mehta, R.H., Rogers, J.G., Hasselblad, V., et al. Association of weight change with subsequent outcomes in patients hospitalized with acute decompensated heart failure. (2009) Am J Cardiol 103(1): 76-81. 26. Pitt, B., Zannad, F., Remme, W.J., et al. The effect of spirnolactone on morbidity and mortality in patients with severe heart failure. (1999) N Engl J Med 341(10): 709-717.

27. Rosenberg, J., Gustafsson, F., Galatius, S., et al. Combination Therapy with Metolazone and Loop Diuretics in Outpatients with Refractory Heart Failiure: An Observational Study and Review of the Literature. (2005) Cardiovas Drugs Ther 19(4): 301-306.

28. Dormans, T.P., Gerlag, P.G. Combination of high-dose furosemide and hydrochlorothiazide in the treatment of refractory congestive heart failure. (1996) Eur Heart J 17(12): 1867-1874.

29. Sica, D.A. Metolazone and its role in edema management. (2003) Congest Heart Fail 9(2): 100-105.

30. De Bruyne, L.K. Mechanisms and management of diuretic resistance in congestive heart failure. (2003) Postgrad Med J 79(931): 268271. 
31. Oster, J.R., Epstein, M., Smoller, S. Combined therapy with thiazide-type and loop diuretic agents for resistant sodium retention. (1983) Ann Intern Med 99(3): 405-406.

32. Klein, L., O'Conor, C.M., Leimberger, J.D., et al. Lower serum sodium is associated with increased short-term mortality in hospitalized patients with worsening heart failiure: results from the outcomes of a prospective trial of milrinone for exacerbations of chronic heart failure (OPTIME-CHF) study. (2005) Circulation 111(19): 2454-2460.

33. Hunt, S.A., Abraham, W.T., Chin, M.H., et al. 2009 focused updated incorporated into the ACC/AHA 2005 guidelines for the diagnosis and management of heart failure in adults: a report of the American College of Cardiology Foundation/American Heart Association Task Force on Practice Guidelines: developed in collaboration with the International Society for Heart and Lung Transplantation. (2009) Circulation 119(14): e391-479.

34. Lasix ${ }^{\circledR}$. Sanofi-Aventis, Bridgewater (2011).

35. Wilcox, C.S. Diuretics. In: B.M. Brenner, F.C. Rector Jr. (Eds). The kidney. WB Saunders, Philadelphia 1991: 2123.

36. Brater, D.C., Chennavasin, P., Seiwell, R. Furosemide in patients with heart failure: shift in dose-response curves. (1980) Clin Pharmacol Ther 28(2):182-186.
37. Brater, D.C., Day, B., Burdette, A., et al. Bumetanide and furosemide in heart failure. (1984) Kidney Int 26(2): 183-189.

38. Eshagian, S., Horwich, T.B., Fonarow, G.C. Relation of Loop Diuretic Dose to Mortality in Advanced Heart Failure. (2006) Am J Cardiol 97(12): 1759-1764.

39. Ellison, D.H. Diuretic resistance: Physiology and therapeutics. (1999) Semin Nephrol 19(6): 581-597.

40. Feenstra, J., Heerdinck, E.R., Grobbee, D.E., et al. Association of nonsteroidal anti-inflammatory drugs with first occurrence of heart failure and with relapsing heart failure: the Rotterdam Study. (2002) Arch Intern Med 162(3): 265-270.

41. Kirchner, K.A., Martin, C.J., Bower, J.D. Prostaglandin E2 but not I2 restores furosemide response in indomethacin-treated rats. (1986) Am J Physiol 250(6 Pt 2): F980-F985.

42. Leto, L., Aspromonte, N., Feola, M. Continuous infusion versus bolus injection of loop diuretics in acute heart failure: a literature review. (2012) G Ital Cardiol (Rome) 13(4): 263-272.
Ommega Online Publishers

Journal Title: Journal of Pharmacy \& Pharmaceutics

Journal Short Name: J Pharm Pharmaceutics
Journal ISSN: 2377-1313

E-mail: pharmacoinformatics@ommegaonline.com Website: www.ommegaonline.org 